\title{
Sensing and adhesion are adaptive functions in the plant pathogenic xanthomonads
}

\author{
Nadia Mhedbi-Hajri ${ }^{1}$, Armelle Darrasse ${ }^{1}$, Sandrine Pigné ${ }^{1}$, Karine Durand ${ }^{1}$, Stéphanie Fouteau ${ }^{2}$, Valérie Barbe ${ }^{2}$, \\ Charles Manceau $^{1}$, Christophe Lemaire ${ }^{3 *}$, Marie-Agnès Jacques ${ }^{1 *}$
}

\begin{abstract}
Background: Bacterial plant pathogens belonging to the Xanthomonas genus are tightly adapted to their host plants and are not known to colonise other environments. The host range of each strain is usually restricted to a few host plant species. Bacterial strains responsible for the same type of symptoms on the same host range cluster in a pathovar. The phyllosphere is a highly stressful environment, but it provides a selective habitat and a source of substrates for these bacteria. Xanthomonads colonise host phylloplane before entering leaf tissues and engaging in an invasive pathogenic phase. Hence, these bacteria are likely to have evolved strategies to adapt to life in this environment. We hypothesised that determinants responsible for bacterial host adaptation are expressed starting from the establishment of chemotactic attraction and adhesion on host tissue.

Results: We established the distribution of 70 genes coding sensors and adhesins in a large collection of xanthomonad strains. These 173 strains belong to different pathovars of Xanthomonas spp and display different host ranges. Candidate genes are involved in chemotactic attraction (25 genes), chemical environment sensing (35 genes), and adhesion (10 genes). Our study revealed that candidate gene repertoires comprised core and variable gene suites that likely have distinct roles in host adaptation. Most pathovars were characterized by unique repertoires of candidate genes, highlighting a correspondence between pathovar clustering and repertoires of sensors and adhesins. To further challenge our hypothesis, we tested for molecular signatures of selection on candidate genes extracted from sequenced genomes of strains belonging to different pathovars. We found strong evidence of adaptive divergence acting on most candidate genes.

Conclusions: These data provide insight into the potential role played by sensors and adhesins in the adaptation of xanthomonads to their host plants. The correspondence between repertoires of sensor and adhesin genes and pathovars and the rapid evolution of sensors and adhesins shows that, for plant pathogenic xanthomonads, events leading to host specificity may occur as early as chemotactic attraction by host and adhesion to tissues.
\end{abstract}

\section{Background}

Deciphering how bacteria adapt to their hosts helps explain how they spread. Host specificity can be established by determining the genes coding virulence factors that are not conserved among strains, which differ in their host range [1]. Virulence-associated genes are expressed during initial host colonisation, multiplication, development of symptoms, and dispersal. Sarkar and

\footnotetext{
* Correspondence: christophe.lemaire@univ-angers.fr; Marie-Agnes. Jacques@angers.inra.fr

${ }^{1}$ UMR077 PaVé, INRA, 42, rue Georges Morel, F-49071 Beaucouzé, France

${ }^{3}$ UMR077 PaVé, Université d'Angers, 42, rue Georges Morel, F-49071

Beaucouzé, France

Full list of author information is available at the end of the article
}

colleagues [1] and Hajri and associates [2] demonstrated that canonical virulence factors such as type III effectors (T3Es) play a critical role in host specificity. T3Es, however, are injected into plant host cells once bacteria have already penetrated into host tissues [3]. Thus, phases preceding infection could also be involved in host specificity and therefore be under selective pressures.

For bacteria to adapt specifically to their hosts, they sense favourable environmental stimuli and then they move toward favourable conditions $[4,5]$. Bacteria have evolved receptors and sensors in their cell walls to detect chemical and environmental signals such as the presence of chemoattractants, chemorepellents, and

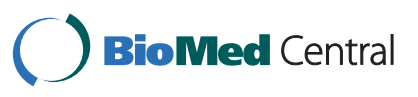


oxygen. They thereby integrate information on their biotic and abiotic environment [6]. Studies on Rhizobia revealed the importance of sensors in the perception of specific host signals early during symbiotic interaction with legumes $[7,8]$. Similarly, Agrobacterium tumefaciens and Ralstonia solanacearum specifically detect various components from root exudates that attract them toward their hosts $[9,10]$.

Environmental signals are mainly detected by Methylaccepting Chemotaxis Proteins (MCPs) and Sensors of Two-Component Regulatory System (STCRS). MCPs are the principal components of the chemotaxis system [4]. Detection of signals by these transmembrane chemoreceptors directs cell locomotion by regulating the histidine kinase CheA, which in turn communicates the information to the flagellar motor by phosphorylating its cognate response regulator CheY $[4,5]$. Changes in the direction or the speed of flagellar rotation modify swimming behaviour, resulting in movement towards higher gradients of attractants and away from high concentrations of repellents [11,12]. In Escherichia coli, chemotaxis proteins cluster in membrane-associated patches $[13,14]$. Interactions within patches contribute to the notable features of this signalling system: high sensitivity, wide dynamic range, signal integration, memory, and adaptation [15]. Besides MCPs, bacteria sense their nutritional environment through TonBDependent Transporters (TBDTs) [16]. A large proportion of TBDT genes are related to plant scavenging and carbohydrate utilisation. TBDTs are over-represented in various bacteria interacting with plants such as Xanthomonas spp. [17].

Adhesion to a surface is a prerequisite for aggregation in a biofilm, which enhances the resistance of bacteria to various biotic and abiotic stresses, favours the coordination of adapted responses to environmental changes, and allows multiplication $[18,19]$. Sensing and adhesion mechanisms are interconnected since biofilm formation is regulated by a chemosensory system [20]. The adhesion step involves surface structures in a broad group of fimbrial and nonfimbrial adhesins. The fimbrial proteins include type IV pili (Tfp), which are polymeric assemblies of the protein pilin $[21,22]$. The nonfimbrial adhesins belong to the autotransporter family (e.g. XadA and YadA proteins) $[23,24]$ and to the two-partner secretion system (e.g. FhaB and YapH proteins) [25].

Each plant pathogenic bacterium belonging to the Xanthomonas genus is able to colonise a restricted variety of plant hosts and microniches. Xanthomonas are exclusively plant-associated bacteria, mainly phyllosphere colonisers, and are not encountered in other environments [26]. Globally, they infect a huge range of economically important plants such as rice, banana, citrus, bean, tomato, pepper, sugarcane, and wheat [26].
The large host range of the genus strikingly contrasts with the typically narrow host range of individual strains restricted to one or several species of a botanical family [27]. Besides their very homogeneous phenotype, xanthomonads differ mainly by their host specificity. This is illustrated in the pathovar subspecific division, which clusters bacterial strains causing similar symptoms on a same host range [28]. A few pathovars are represented by polyphyletic genetic lineages i.e. pv. phaseoli [29] and pv. dieffenbachiae [30]. The two lineages of the latter pathovar are pathogenic on different hosts (Anturium and Dieffenbachia) and hence may be considered as separate pathovars [30].

The 12 available Xanthomonas genomes http://www. genomesonline.org/ revealed a huge number of genes encoding chemotactic sensors, systems sensing the nutritional environment of the cell (MCPs, TBDTs and STCRS), and attachment structures [17,31,32]. This large number reflects a high degree of adaptability and the presence of mechanisms and structures involved in the exploration of the bacterial environment and adaptive colonisation. This led us to hypothesize that determinants responsible for bacterial host specificity are expressed starting from the establishment of chemotactic attraction by host tissues and adhesion on phylloplane. Thus, characterizing repertoires of genes encoding sensors and adhesins will provide information about the interaction and the adaptation of bacteria to their host plants. Here we characterized the distribution of genes encoding MCPs, STCRS, TBDTs, and adhesins in a large collection of strains belonging to different pathovars in several species of Xanthomonas. We also tested for molecular signatures of selective pressures on candidate genes. Two types of outcomes were expected: (i) strong purifying selection acting on genes involved in recognition of common structures of plant tissues and (ii) adaptive divergence on genes coding for sensors and adhesins used for colonisation of specific niches. We identified a large variety of repertoires generally fitting with the pathovar clustering. Adaptive divergence was found to affect most candidate genes. These findings provide insight on the evolutionary importance of chemotactic attraction and adhesion in the host specificity of plant pathogenic bacteria.

\section{Results \\ Identification and selection of genes}

Based on data mining, we identified genes involved in bacterial attraction, sensing, and adhesion to host. We extracted sequences of genes from four complete genome sequences (X. axonopodis pv. vesicatoria (Xav) strain 85-10, X. axonopodis pv. citri (Xac) strain 306, X. campestris pv. campestris (Xcc) strain ATCC33913, and $X$. oryzae pv. oryzae (Xoo) strain KACC10331). These 
four bacteria have different host ranges and are phylogenetically distant. First, a list containing 320 genes involved in sensing, chemotaxis, motility, and adhesion was established using BLAST analysis. This list includes 30 genes encoding MCPs, 17 genes encoding chemotactic protein, 34 genes encoding flagellar components, 31 genes involved in Tfp biogenesis, 10 genes encoding nonfimbrial adhesins, 115 genes encoding TBDTs, and 83 genes encoding STCRS (See additional file 1: Table A1 for the complete list of genes involved in sensing and adhesion in xanthomonads). Second, for selection detection analyses, we selected genes that were ubiquitous in the four genomes, for which polymorphism was observed and that encodes proteins acting upstream in regulation cascades. Hence, we selected 70 candidate genes: 28 genes encoding TBDTs, 7 genes encoding STCRS, 25 genes encoding MCPs, 2 genes encoding Tfp sensors, 1 gene encoding Tfp assembly ATPase, and 7 genes encoding adhesins.

\section{Characterization of repertoires of MCPs, STCRS, TBDTs, and adhesins}

We investigated the distribution of the 70 selected genes in 173 strains belonging to different lineages in Xanthomonas spp. by PCR (See additional file 2: Table A2 for the list of bacterial strains). Three independent PCR reactions with two different sets of primers and three DNA batches were used to monitor the presence of genes in the strain collection. A gene was considered absent when no signal was obtained. But with this approach, one cannot rule out that some genes that we considered as potentially absent may have undergone several point mutations in the primer regions, which could result in divergence sufficient to prevent amplification through several PCRs. Every PCR result on the DNA of $X$. axonopodis pv. phaseoli GL fuscans strain CFBP4834 was confirmed by BLAST analysis on the draft genome sequence of this strain (our unpublished data). No discrepancies were observed for this strain in any of the 70 candidate genes.

MCPs, STCRS, TBDTs, and adhesin repertoires contained three categories of genes based on their presence/absence (Figure 1): first, ubiquitous genes showing a broad distribution among strains (e.g. XCV1940, detected in all strains, and pils, detected in most strains); second, genes displaying a variable distribution since they were not detected in several strains (e.g. XCV1954 and XCV2103); third, genes found in only one species (e.g. XAC3768 and xadA2, detected only in $X$. axonopodis, and XCC0324 and XCC0276, found only in $X$. campestris).

Most bacterial lineages in Xanthomonas spp. displayed unique repertoires of MCPs, STCRS, TBDTs, and adhesins (Figure 1). Our results showed that 28 of the 34 pathovars and genetic lineages of Xanthomonas spp. had distinct repertoires. In contrast, different pathovars may display the same repertoire, as do pathovars alfalfae and ricini, pathovars allii and citrumelo, and pathovars vignicola and genetic lineage GL2 of pathovar phaseoli. A large variability in the number of genes constituting repertoires was observed among pathovars with $X$. ory$z a e$ strains harbouring the smallest repertoires, whereas strains of $X$. axonopodis pv. citri displayed the largest repertoires.

Repertoires of MCPs, STCRS, TBDTs, and adhesins were almost identical within pathovars alfalfae, begoniae, malvacearum, manihotis, musacearum, and oryzae. Regarding pathovar anacardii, strains isolated from Mangifera indica (CFBP2913 and CFBP2914) displayed repertoires that differed by three genes (XAC3050, XCV3187 and $f h a B$ ) from the repertoires of the strains isolated from Anacardium occidentale (CFBP7240, CFBP7241, CFBP7242 and CFBP7243). The diversity observed among repertoires in pathovar allii could not be associated with either the genetic diversity or the known host of isolation [33] (See additional file 2: Table A2 for the list of host of isolation of each bacterial strain).

Based on the presence/absence matrix, clustering of strains from different pathovars could be linked in some cases to the host plant (Figure 2). Strains that were grouped were of the pathovar vignicola, which infect Vigna unguiculata and V. sinensis, and strains of GL2 of pathovar phaseoli, which infect Phaseolus vulgaris. The hosts of isolation of these strains belong to the same botanical family (Fabaceae) and are closely related [34]. Also clustered together were strains phylogenetically distant [30] and belonging to different species (CFBP5823 of $X$. axonopodis pv. vasculorum and CFBP5830, CFBP5831, and CFBP1215 of X. vasicola pv. vasculorum) but isolated from the same host, Saccharum officinarum (Figure 2).

\section{Positive selection acting on $X$. axonopodis and $X$. campestris genes encoding MCPs and adhesins}

The McDonald-Kreitman (MK) tests for adaptive divergence done on 24 candidate genes (MCPs, adhesins, and Tfp sensors) and four housekeeping genes from three sequenced strains of $X$. axonopodis and three of $X$. campestris revealed that 13 of the 24 candidate genes showed robust signatures of adaptive divergence (Figure 3 and see additional file 3: Table A3 for the results of the MK tests). The four housekeeping genes did not display any signal of positive selection after Bonferroni correction. Significant signatures of adaptation were found in the divergence between $X$. axonopodis and $X$. campestris sequences on 11 genes (7 MCPs, 2 adhesins, and 2 Tfp sensors) of the 24 for which analysis 


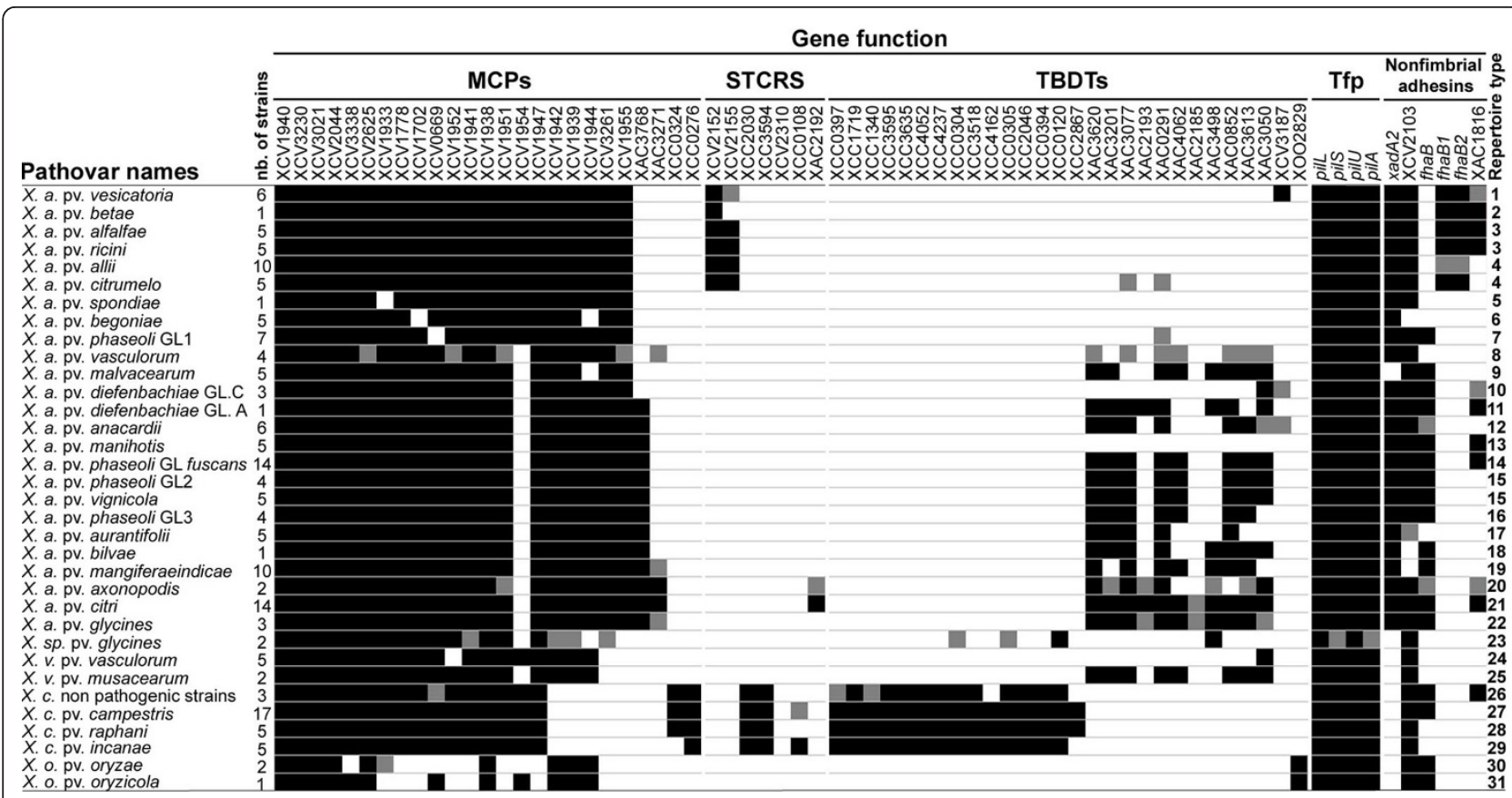

Figure 1 Distribution of genes involved in sensing and adhesion among lineages of Xanthomonas spp. Black and white squares represent the presence and the absence, respectively, of the corresponding gene in at least $80 \%$ of strains of a pathovar or a genetic lineage. Grey squares indicate that the presence of the gene is variable among strains of the lineage. Thirty one repertoire types were identified on the basis of the presence-absence of genes under study. At least three independent PCR reactions were performed to ascertain the presence/ absence of each gene. $X . a .:$. axonopodis; $X . v$ : X. vasicola; $X$. c.: X. campestris and X. o.: X. oryzae.

was possible. Using XocBLS256 as an outgroup showed that diversifying selection preferentially affected the $X$. axonopodis clade.

Positive selection was also tested using the branch-site model implemented in PAML within $X$. axonopodis on candidate genes already tested with the MK test. The branch-site model allows detecting selection at a few codons (sites) on a specific lineage (branch). Strains of different pathovars in $X$. axonopodis (strains Xav85-10, Xac306 and XapCFBP4834) occupy distinct habitats, exploit distinct niches, and cause different diseases on different host-plants (Lycopersicon esculentum and Capsicum sp., Citrus sp. and Phaseolus vulgaris, respectively). We hypothesised that these strains representing different pathovars would have undergone selection differently for correspondingly distinct adaptations. For each gene, three tests were applied, each considering a different foreground branch corresponding to each of the three pathovars. Results revealed that sets of genes under positive selection in Xav85-10, Xac306, and XapCFBP 4834 were distinct. Indeed in the case of pathovar vesicatoria (Xav85-10), the set of genes under selection included XCV1940 and XCV1942. Regarding pathovar citri (Xac306), the set included XCV1702, XCV1945, and $x a d A 1$. Finally, in pathovar phaseoli (XapCFBP4834), positive selection was detected on genes XCV1945 and XCV1951. Interestingly, XCV1945 was found to be under positive selection on both pathovars citri and phaseoli. However, Bayes Empirical Bayes (BEB), which estimates the probabilities of each site on the foreground branch evolving under positive selection, identified different sites either in Xac306 or XapCFBP4834 (Table 1). For each gene, from 1 to 10 sites were found under selection. Sixteen of the 22 sites under selection were in conserved domains in the proteins (Table 1 and Figure 4).

\section{Discussion}

The early phases of host-colonisation are crucial for pathogenic bacteria [35]. However, little is known about the importance of early phases in determining host-specificity for plant pathogenic bacteria. Emphasis has been put on later phases of infection, as illustrated by the demonstration of the role of T3Es in host-specificity $[1,2,36]$. Host-recognition can be considered the first instance of host-pathogen interaction allowing bacteria to colonise. The importance of chemotaxis in plant-bacteria interactions has been clearly documented in some cases. For example the chemotactic mutant Ralstonia solanacearum is unable to colonise its host when inoculated into the soil, whereas it remains fully pathogenic when infiltrated inside plant 


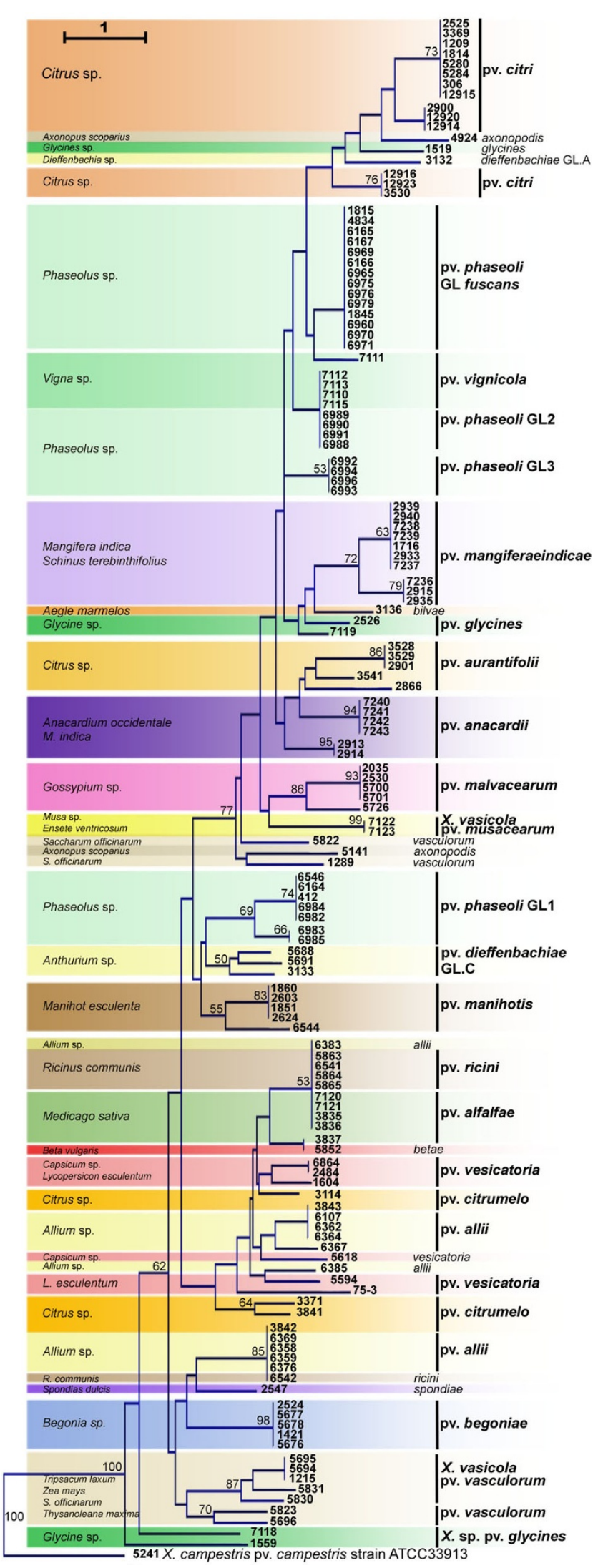

Figure 2 Dendrogram constructed based on presence/absence of candidate genes in strains of Xanthomonas spp. The dendrogram was constructed with the Neighbour-Joining method using Euclidean distance and rooted with strain CFBP5241 of X. campestris pv. campestris. Confidence on nodes was established using 1000 bootstrap replicates. Only bootstrap values above 50\% are reported. 


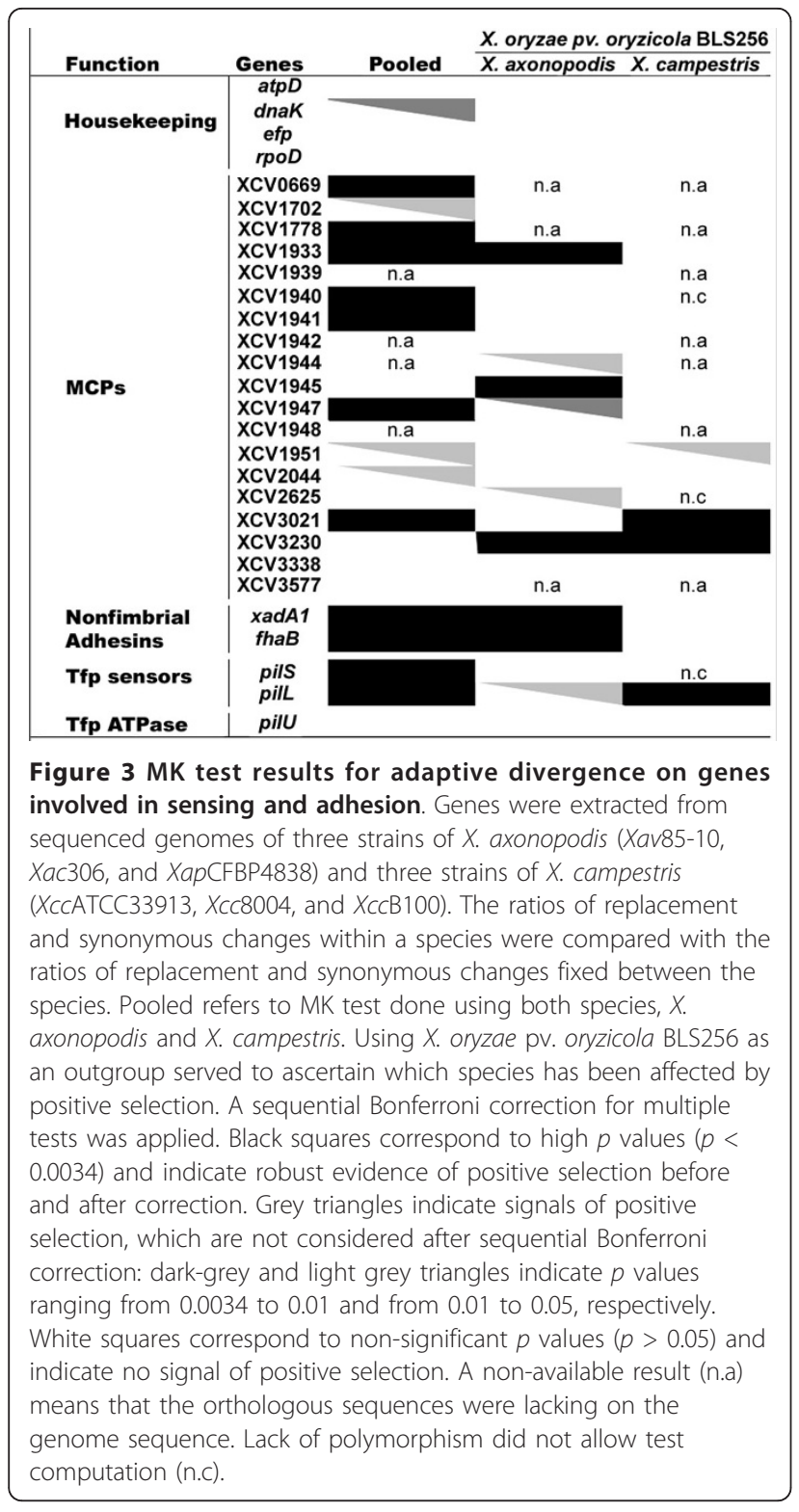

tissues [10]. Thus evolutionary processes of host-specificity would also be driven by selective forces at the very first steps of host-colonisation. Our data show evidence of such adaptive processes for numerous genes involved in chemotactic attraction, environment sensing, and adhesion to surfaces. These mechanisms precede the infection of a plant by xanthomonads. The mechanisms facilitating plant penetration and thus allowing infection are chemotaxis, aerotaxis, and fast multiplication inside host tissue, which relies on adhesion.

According to MK-tests results, many candidate genes undergo positive selection during bacterial colonisation on plant tissue. Of the 24 genes common among repertoires of the studied pathovars (vesicatoria, citri, and
Table 1 Sites under positive selection in candidate genes

\begin{tabular}{|c|c|c|c|c|c|}
\hline Strain & $\begin{array}{l}\text { Target } \\
\text { gene } \\
\text { name }\end{array}$ & Residue & $\begin{array}{l}\text { Residue } \\
\text { position }\end{array}$ & $\begin{array}{c}p(\omega>> \\
1)^{\mathrm{b}}\end{array}$ & $\begin{array}{l}\text { Interpro } \\
\text { accession }\end{array}$ \\
\hline \multirow[t]{3}{*}{ Xav85-10 } & XCV1940 & $P$ & 79 & 0,920 & - \\
\hline & XCV1942 & 1 & 48 & 0,910 & - \\
\hline & XCV1942 & $\mathrm{R}$ & 131 & 0,948 & - \\
\hline \multirow[t]{6}{*}{ Хac306 } & XCV1702 & Q & 622 & 0,929 & IPR004089 \\
\hline & XCV1945 & D & 59 & 0,909 & - \\
\hline & XCV1945 & S & 92 & 0,982 & - \\
\hline & xadA1 & Y & 390 & 0.903 & - \\
\hline & xadA1 & Q & 880 & 0.947 & IPR008640 \\
\hline & xadA1 & E & 882 & 0.951 & IPR008640 \\
\hline \multirow[t]{13}{*}{ ХapCFBP4834 } & XCV1945 & S & 352 & 0,955 & IPR004089 \\
\hline & XCV1945 & S & 658 & 0,954 & IPR004089 \\
\hline & XCV1945 & Q & 685 & 0,945 & IPR004089 \\
\hline & XCV1951 & S & 780 & 0,971 & IPR004089 \\
\hline & XCV1951 & V & 814 & 0.924 & IPR004089 \\
\hline & XCV1951 & $\mathrm{E}$ & 847 & 0.968 & IPR004089 \\
\hline & XCV1951 & V & 851 & 0.984 & IPR004089 \\
\hline & XCV1951 & $\mathrm{N}$ & 855 & 0.962 & IPR004089 \\
\hline & XCV1951 & V & 858 & 0.975 & IPR004089 \\
\hline & XCV1951 & K & 859 & 0.989 & IPR004089 \\
\hline & XCV1951 & $\mathrm{R}$ & 872 & 0.982 & IPR004089 \\
\hline & XCV1951 & $\mathrm{T}$ & 876 & 0.993 & IPR004089 \\
\hline & XCV1951 & $A$ & 880 & 0.982 & IPR004089 \\
\hline
\end{tabular}

Genes were extracted from genomic sequences of three strains belonging to three pathovars of $X$. axonopodis (vesicatoria, citri and phaseoli). Sites were identified using Branch-site model A (model $=2$ NSites $=2$ ) compared to the null model with $\omega$ fixed to 1 .

a: National Center for Biotechnology Information (NCBI) gene name. XCV indicates a gene in $X$. axonopodis pv. vesicatoria 85-10 genome.

$\mathrm{b}^{\mathrm{b}}$ : $\omega$ estimates the parameter $D_{\mathrm{n}} / D_{\mathrm{s}}$ for each site and $p(\omega>1)$ represents posterior probability of sites with $\omega>1$.

phaseoli) of $X$. axonopodis and $X$. campestris pv. campestris, nearly half are subject to positive selection. This proportion is almost equal among the two gene families (MCPs and adhesins). The McDonald-Kreitman procedure tests for adaptive divergence between two species. The test is known to be robust to non-equilibrium demography $[37,38]$ and to recombination [39]. Using a small sample size would reduce the power of the test. The lack of power to detect selection would increase the risk of false negatives. Thus our results are conservative and can not be interpreted as false positive. Charlesworth and Eyre-Walker [40] showed that about 50\% of amino-acid substitutions surveyed in the enteric bacterial genomes were subject to adaptive evolution. Thus both recognition and adhesion should be considered as selective steps for bacterial colonisation. To our knowledge this is the first report of positive selection acting on MCPs in plant-pathogenic bacterium. Our results are consistent with those of Chen et al. [41] and Petersen et al. [42] showing that positive selection acts on genes 


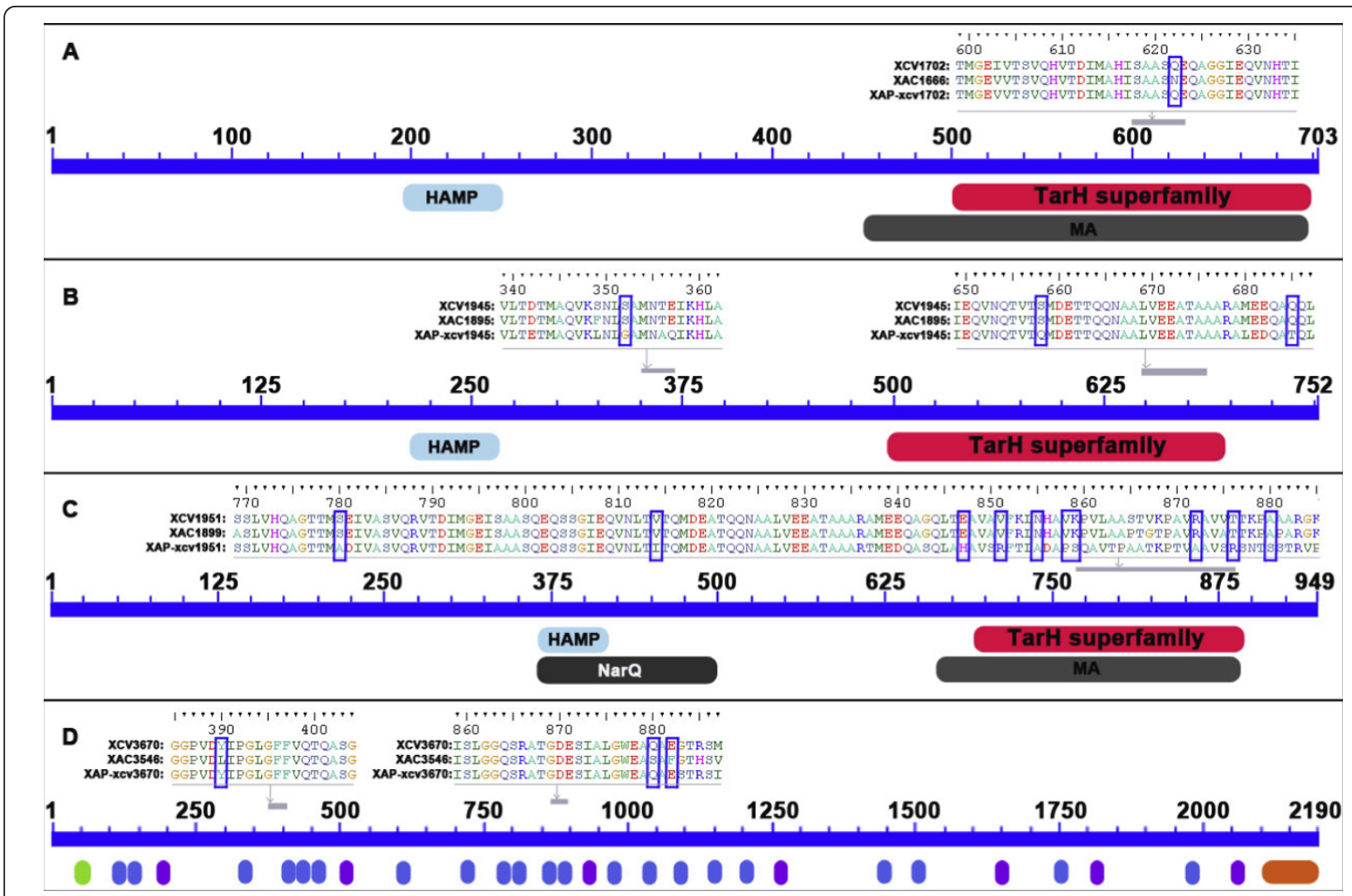

Figure 4 Schematic representations of examples of sites under selection and conserved domains in MCPs (A, B, and C) and adhesins (D). In the upper parts of each panel the sequence alignments of proteins are presented for parts containing sites under selection. The orthologous sequences collected from genome sequences of Xcv85-10, Xac306, and XapCFBP4834 were aligned using ClustalW according to the translated amino-acid sequences, manually performed using BIOEDIT. Sites that were found under selection are highlighted by green frames. In the lower parts of the panels, conserved domains are represented. HAMP: Histidine kinase, Adenylyl cyclase, Methyl-accepting protein, and Phosphatase domain. HAMP is a signalling domain that occurs in a wide-variety of signalling proteins. TarH superfamily: Taxis toward Aspartate and Related amino acids and Homologs. MA: Methyl-accepting chemotaxis-like domain (chemotaxis sensory transducer), thought to undergo reversible methylation in response to attractants or repellents during bacterial chemotaxis. NarQ: signal transduction histidine kinase, nitrate/ nitrite-specific. Annotation bars coloured in grey refer to multi-domains that are excluded from domain-domain neighbouring. In the D panel, green, blue, purple, and orange ovals symbolised TAT signal, Hep-Hag motif, HIM motif and YadAlike, C-terminal domain, respectively.

encoding surface structures of E. coli cell. These genes encode regulators of LPS O-antigen chain length, putative adhesins that affect biofilm formation, ferrichromeiron receptors, two outer membrane porins, and more $[41,42]$. In xanthomonads, the extracellular appendage of the Hrp pilus evolved under the constraint of positive selection likely to avoid recognition by plant defense surveillance systems [43].

Most sites that were found under selection in candidate genes by PAML analysis were located in conserved domains predicted to play a role in perception for MCPs and in adhesion for XadA1. Indeed, the Tar domain of chemoreceptors directly binds to aspartate and related amino acids [44]. The Hep-Hag motif is found in the passenger domain of adhesins [45]. This domain is known to contribute to the binding activity of invasins/agglutinins [23]. This result is another argument in favour of selection pressures acting on these genes in link with the ecological behaviour of the strains. Detection of positive selection using the branchsites model implemented in PAML has some power limitations especially if only three sequences are used. Our results, however, should be considered conservative as they reduced the number of false positives.

Many bacteria assemble multifunctional proteic structures on their surfaces that serve for adhesion. This feature might be an adaptation to different environmental conditions and, in the case of pathogenic bacteria, to different hosts or host tissues [46]. In fact, adhesins are involved in various processes leading to host colonisation and transmission to seed by plant-pathogenic bacteria. For example, Tfp serves remarkably diverse functions, including twitching motility, cell to cell adhesion, and thus microcolony and biofilm formation [21]. Tfp is an important virulence factor for vascular and non vascular plant pathogens $[47,48]$. Moreover, 
Darsonval and colleagues [48] showed that PilA is involved not only in adhesion but also in transmission to seed, and the mutation of pilA in strain CFBP4834 of $X$. axonopodis pv. phaseoli GL fuscans leads to lower pathogenicity on bean (P. vulgaris). Additionally, YapH, an hemagglutinin, is required for adhesion to seed, leaves, and abiotic surfaces.

An interesting consequence of strong differential selection pressures by host is a specialisation at some early steps (i.e. chemotactic attraction) of host colonisation by xanthomonads. Character displacement at early stage of host colonisation should make infection more efficient by preventing competition for habitat between strains $[49,50]$. In fact, xanthomonads are known to be phenotypically very homogeneous except in pathogenicity. Lack of selective pressures in host colonisation would lead to colonisation by a wide range of incompatible strains. Colonisation of specialized pathovars would therefore be less successful. Indeed, resource allocation would be redirected in favour of competition detrimental to pathogenicity. Finally, such host-isolation could act as an ecological isolating barrier to limit recombination between differentially adapted pathogenic strains. As in eukaryotic organisms, ecological differences in bacteria are known to promote speciation [51]. Indeed, habitat sharing would allow recombination between strains that belong to different pathovars and that consequently produce strains that may reveal genetic incompatibilities.

This comparative analysis of repertoires of MCPs, STCRS, TBDTs, and adhesins provides useful insight into bacterial behaviour. First, the number of MCPs and more generally sensors is higher in Xanthomonas strains than in E. coli and Salmonella [52]. E. coli and Salmonella have only five MCPs whereas strains Xav85-10, Xac306, and XccATCC339313 have about 20 MCPs; strain XooKACC10331 has only about 10 MCPs. The large numbers (14 in Xav85-10, 10 in Xac306, 8 in XccATCC339313, and 7 in XooKACC10331) of MCPs and other sensors repeated in tandem are unusual in bacteria, suggesting a prominent role in the life style of Xanthomonas [17,31,32]. Second, repertoires of MCPs, STCRS, TBDTs, and adhesins differed among the majority of pathovars and genetic lineages belonging to the tested Xanthomonas spp. and displaying different host range. Repertoires of genes coding sensors and adhesins comprised core and variable gene suites. Some genes under study were not intra-specifically conserved and hence belong to the accessory genome. Repertoires of genes involved in attraction and adhesion may evolve by gene gain or loss, probably after duplication events. In the case of Drosophila, the size of repertoires of genes encoding olfactory and gustatory receptors varies through gene duplication, pseudogenization, and gene loss. The changes among species of Drosophila show that these receptors have changed during species divergence, and their evolution might reflect species' adaptation to their chemical environment [53]. Similarly, in xanthomonads, the variable set of sensors and adhesins may be involved in the recognition of specific components allowing strain adaptation to a particular set of hosts. Moreover, we identified signals of adaptive divergence have been identified on such genes of the variable set.

This study showed that among the same genus, Xanthomonas, the majority of pathovars and genetic lineages belonging to different species ( $X$. axonopodis, $X$. campestris, $X$. vasicola, and $X$. oryzae) displayed different and unique repertoires of MCPs, STCRS, TBDTs, and adhesins while they displayed different host range. Note that the distribution of sensor and adhesin genes does not necessarily correlate with strain phylogeny. Indeed, bacteria as phylogenetically distant as $X$. axonopodis pv. vasculorum and X. vasicola. pv. vasculorum [30] share a common repertoire of sensor and adhesin genes (Figure 2) and a common host: sugarcane. This case illustrates the sharing of a common ecological niche (symptomatic host) by two phylogenetically distant bacteria.

Our results suggest that adaptation to host involves pathoadaptation but also asymptomatic colonisation steps. Indeed, several pathovars and genetic lineages shared the same repertoires whereas they are known to infect different crops. This means that they could share the same asymptomatic host range but develop symptoms on a restricted number of different host plants. This is the case for the pathovar vignicola and the genetic lineage GL2 of pathovar phaseoli. X. axonopodis pv. phaseoli GL2 and pv. vignicola strains may detect similar plant-originated molecules potentially conserved among their host plants. This hypothesis is supported by the fact that $X$. axonopodis pv. phaseoli GL2 and vignicola both infect legumes. X. axonopodis pv. phaseoli GL2 infects Phaseolus spp. and X. vignicola infects Vigna unguiculata; these legumes belong to the Milletioid clade and are phylogenetically closely related [33]. Interestingly, cross inoculations would provide insight on the ecological behaviours of these two pathogens (survival, colonisation and chemotaxis responses). The four genetic lineages (fuscans, GL1, GL2, GL3) of pathovar phaseoli, which all share a common host ( $P$. vulgaris), present distinct repertoires of MCPs, STCRS, TBDTs, and adhesins. Genetic lineage fuscans, GL2, and GL3 are phylogenetically closely related and belong to rep-PCR group 9.6 whereas GL1 is distant and belongs to rep-PCR group 9.4 [2,30,54]. These four distinct genetic lineages have different T3E repertoires but clustered together on the dendrogram constructed on the 
matrix of presence/absence of T3Es genes, supporting the hypothesis of an adaptive pathological convergence on bean [2]. Our results suggest that, upstream of the invasive pathological stage, the four genetic lineages have different ecological behaviours. Colonisation does not necessarily lead to infection and then may not be under the same adaptive processes as host infection. We can speculate that each lineage of $X$. axonopodis pv. phaseoli can be found on different asymptomatic hosts.

Overall, our findings indicate that plant pathogenic bacteria belonging to different pathovars have evolved different set of genes allowing them to specifically detect favourable hosts on which they can settle. These results support a recent theory termed inverse-gene-for-gene in which infectiousness is determined by pathogen recognition of hosts signals and/or receptors [55]. This theory is an alternative to the gene-for-gene model in which the pathogen is recognized by the host., Here, in agreement with this theory we show that many pathogen genes involved in host recognition evolved under adaptive divergence. Such a selective pressure on genes encoding for recognition of specific hosts strongly accounts for coevolutionary dynamics where pathogens are always adapting their sensors in response to hosts changes in exudates and surface structures.

Plant pathogenic xanthomonads are associated with aerial parts of plants. They are not usually encountered in other environments. Plant pathogenic pseudomonads colonise non-host habitats such as snow or water [56]. Our attempts to isolate xanthomonads from such environments were, however, unsuccessful (our unpublished data). Saprophytic survival of xanthomonads in soil is very poor. Apart from their primary host, many xanthomonads can survive for long periods in association with weeds that grow naturally in crops. It is not yet known which weeds are susceptible to colonisation by each plant pathogenic xanthomonad. We refer in our study to the main crop contaminated by each pathovar, which certainly represents the major opportunity for bacterial multiplication.

\section{Conclusions}

This study showed that the majority of the tested pathovars belonging to different species of Xanthomonas (X. axonopodis, $X$. campestris, $X$. vasicola, and $X$. oryzae) displayed unique repertoires of genes coding proteins involved in sensing (MCPs, STCRS, TBDTs) and adhesion. Our data show evidence of adaptive processes for numerous genes involved in chemotactic attraction, environment sensing, and adhesion to surfaces. Most sites that were found under selection in candidate genes were located in conserved domains predicted to play a role in perception or in adhesion. Xanthomonads are plant-associated bacteria and are not known to efficiently colonise other environments. Hence, we argue that the gene evolution we observed may reflect pathovar adaptation to the host-plant environment.

The molecular variation of genes involved in host recognition and adhesion to host tissues clearly shows adaptation begins at the very first steps of host colonisation. We suggest that such adaptive divergence at early phases of host colonisation would act as an ecological isolating barrier to promote speciation. However, such a process could have appeared after isolation by genes involved in infection, like T3Es. In this case, adaptation would be a consequence rather than a cause. Despite their high evolutionary relevance, the respective roles of host recognition and host infection in promoting ecological reproductive barriers remain to be elucidated.

\section{Methods}

The xanthomonad strains used in this study were named following the nomenclature proposed by Vauterin et al. [27,57] and are presented in Additional file 2. Genes encoding MCPs, STCRS, TBDTs, and adhesinrelated genes were selected from sequenced genomes of Xav85-10, Xac306, XccATCC33913, and XooKACC10331 http://www.ncbi.nlm.nih.gov. These genes were identified according to their function-based assignment in the NCBI website to cell motily (COG N), signal transduction mechanisms (COG $\mathrm{T}$ ), and inorganic ion transport and metabolism (COG P) classes and according to Thieme et al. [32] for fimbrial and nonfimbrial adhesin genes. Using Blastx analysis with default parameters [58], we identified orthologous genes (more than $80 \%$ identity on more than $80 \%$ of the length of the sequence) in each of the four reference genomes. Hence, a list containing 320 genes involved in sensing, chemotaxis, motility, and adhesion was established (See Additional file 1: Table A1). This list was refined by analysing the functional-domain composition of the genes. We selected genes encoding MCPs containing periplasmic domains (e.g TAR, PRK09793, PAS and HAMP domains). Regarding genes encoding TBDTs and STCRS, we selected receptor and sensor parts, respectively, based on the gene description and gave priority to genes identified in only one of the four sequenced strains. We discarded genes that encoded cytoplasmic proteins such as chemotactic proteins (CheA-Z) and genes encoding flagellar components characterised by a very low polymorphism of presence or absence and sequence conservation.

Primer design was based on the alignment of orthologous sequences collected from the four genomes in conserved fragments, taking care to avoid amplification of other genes that share domains with the target. Then, sets of primers were validated both by in silico specific gene amplifications (Amplify software version 3.1.4) and 
by specific gene amplification using PCR with genomic DNA extracted from the four sequenced genomes previously mentioned. PCR reactions were prepared as described previously [2]). To characterise repertoires, PCRs were performed using one set of extracted genomic DNA ( $1 \mathrm{ng})$ and two sets of boiled bacterial cells $\left(3 \times 10^{8}\right.$ $\mathrm{cfu} \mathrm{ml}^{-1}$ ) per strain. Preliminary dot blot hybridisations were done to validate PCR results. We designed probes for specific (XCC0324) and variable (XCV2103 and XAC1816) genes. Hybridisations were performed as described previously [2] on extracted DNA (250 ng) from reference strains. Positive signals were obtained for all strains, in contradiction with the results expected based on bioinformatic analysis of presence/absence on the sequenced-genomes from the same strains. These discrepancies can be explained by the structure of these modular genes, which share motifs in functional domains (e.g. HAMP, hemagglutinin, or autotransporter domains) and consequently have many sequence similarities. As dot blot could not be used to confirm the absence of signal we designed, whenever possible, another set of primers for each non-ubiquitous gene. Generally, two sets of primers were used for each gene on three batches of DNA (See Additional file 4: Table A4 for the sequences of primers). Finally, a fourth set for result validation was obtained using the draft genome sequence of $X$. axonopodis pv. phaseoli GL fuscans strain CFBP4834 (our unpublished data). Every PCR result on the DNA of this strain was confirmed by BLAST analysis [56].

Based on the presence/absence matrix of MCPs, STCRS, TBDTs, and adhesin genes obtained by PCRs for each of the 173 strains of Xanthomonas sp., we constructed a dendrogram using Euclidean distance and Neighbour-Joining method, which was visualised using PAST version 1.90 software [59].

Tests for positive selection were performed on orthologous sequences collected from the genome sequences of Xav85-10, Xac306 and XapCFBP4834, XccATCC33913, $X c c 8004$ and $X c c B 100$, and XocBLS256. Twenty four candidate genes, including 19 MCPs genes and 5 adhesinrelated genes, were analysed together with 4 housekeeping genes. The nucleotide sequences were aligned using ClustalW [60] according to the translated amino-acid alignment in order to keep the codon structure of the coding sequences. Adjustments on multiple alignments were manually performed using BIOEDIT version 7.0.9.0 program [61]. Annotation of domains was performed by using the Conserved Domain Database available [62] in NCBI web site. The DNASP software package [63] was used to perform several tests for positive selection using the MK test [64]. The MK test is a simple method to contrast the patterns of within-species polymorphism and between-species divergence at synonymous and nonsynonymous (replacement) sites in the encoding region of a gene. The MK test evaluates whether an excess of replacement mutations versus synonymous mutations had been fixed between the two species compared with replacement and synonymous polymorphisms within each species. A significant ratio of fixed replacement to fixed synonymous mutations leads to rejecting the neutral mutation hypothesis and indicates adaptive fixation of selectively advantageous mutations. Three MK test conditions were applied (i) to detect adaptive divergence signals between two species ( $X$. axonopodis vs $X$. campestris) and (ii) to ascertain which species has been affected by positive selection by assigning the fixed replacement changes to $X$. axonopodis and/or X. campestris using $X$. oryzae pv. oryzicola (Xoc) strain BLS256 as outgroup strain. The significance of MK results was established by the Fisher exact test. Bonferroni correction for multiple tests [65] was hand-computed and applied on MK test results. Testing for positive selection acting at a specific locus on a particular pathovar (i.e. branch) was performed using the branch-site model A of Yang and Nielsen [66] implemented in the CODEML program of the PAML package (version 3.14) [66,67]. Testing was performed on each gene previously analysed for adaptive divergence. Three sequenced-genome strains of different pathovars in $X$. axonopodis (pvs. vesicatoria, citri, and phaseoli) were used. For each gene, three tests were done by labelling one branch as foreground at a time. Model selection was performed using likelihood ratio test. In contrast to other methods of selection detection, the Branch-site model allows for small numbers of taxa.

\section{Additional material}

\begin{abstract}
Additional file 1: Table A1 Genome mining: identification of genes involved in sensing and adhesion in xanthomonads. Genes were extracted from 4 complete sequenced genomes of xanthomonads available in the NCBI website
\end{abstract}

Additional file 2: Table A2 List of bacterial strains used in this study and their repertoires of candidate genes. Strains belonged to 25 pathovars of Xanthomonas spp. MCPs, STCRS, and TBDTs are involved in sensing while Tfp sensors and adhesins are involved in adhesion. Presence (black square) or absence (white square) of an orthologous sequence was determined by at least three independent $P C R$ reactions

Additional file 3: Table A3 Genes under positive selection. Results of the MK tests for positive selection on 4 genes encoding housekeeping genes, 19 genes encoding MCPs, and 5 adhesin-related genes

Additional file 4: Table A4 Sequences of pairs of primers used to amplify candidate genes. The annealing temperature of the PCRs and the lengths of the amplified fragments are also indicated.

\section{Acknowledgements and funding}

We thank Ralf Koebnik and Tristan Boureau for critical reading of the manuscript. N Mhedbi-Hajri was supported by a grant from the Tunisian Ministry of Education and Research. We acknowledge English proofreading of the manuscript by Gary Burkhart. This study was parts of programs funded by the Region Pays de la Loire and by the Plant Health and Environment Department of INRA. 


\section{Author details}

'UMR077 PaVé, INRA, 42, rue Georges Morel, F-49071 Beaucouzé, France.

${ }^{2}$ CEA/DSV/IG/Genoscope, 2 rue Gaston Cremieux, 91057 Evry Cedex 06, France. ${ }^{3}$ UMR077 PaVé, Université d'Angers, 42, rue Georges Morel, F-49071 Beaucouzé, France.

\section{Authors' contributions}

$\mathrm{NMH}$ design and performed the experiments, analyzed the data and drafted the manuscript. AD participated in the design of the study, in the construction of gene repertoires, in the data analyses and in the writing. SP and $\mathrm{KD}$ participated in the construction of gene repertoires. SF and VB performed sequencing of CFBP4834 genome. CM participated in the design of the study and revised the manuscript. $\mathrm{CL}$ analyzed the data and wrote the paper. MAJ conceived the study, design the experiments, analyzed the data and wrote the paper. All authors read and approved the final manuscript.

Received: 18 January 2011 Accepted: 11 March 2011 Published: 11 March 2011

\section{References}

1. Sarkar SF, Gordon JS, Martin GB, Guttman DS: Comparative genomics of host-specific virulence in Pseudomonas syringae. Genetics 2006, 174(2):1041-1056.

2. Hajri A, Hunault G, Lardeux F, Lemaire C, Manceau C, Boureau T, Poussier S: A «Repertoire for Repertoire» Hypothesis: Repertoires of Type Three Effectors are Candidate Determinants of Host Specificity in Xanthomonas. PLOS ONE 2009, 4:e6632.

3. Boureau T, ElMarouf-Bouteau H, Garnier A, Brisset MN, Perino C, Pucheu I, Barny MA: DspA/E, a type III effector essential for Erwinia amylovora pathogenicity and growth in planta, induces cell death in host apple and nonhost tobacco plants. Mol Plant Microbe Interact 2006, 19(1):16-24.

4. Rao CV, Ordal GW: The molecular basis of excitation and adaptation during chemotactic sensory transduction in bacteria. Contrib Microbiol 2009, 16:33-64.

5. Vladimirov N, Sourjik V: Chemotaxis: how bacteria use memory. Biological Chemistry 2009, 390(11):1097-1104.

6. Szurmant $\mathrm{H}$, Ordal GW: Diversity in chemotaxis mechanisms among the bacteria and archaea. Microbiol Mol Biol Rev 2004, 68(2):301-319.

7. Yost CK, Rochepeau P, Hynes MF: Rhizobium leguminosarum contains a group of genes that appear to code for methyl-accepting chemotaxis proteins. Microbiology 1998, 144(7):1945-1956.

8. Yost CK, Clark KT, Del Bel KL, Hynes MF: Characterization of the nodulation plasmid encoded chemoreceptor gene mcpG from Rhizobium leguminosarum. BMC Microbiol 2003, 3:1.

9. Hawes MC, Smith LY: Requirement for chemotaxis in pathogenicity of Agrobacterium tumefaciens on roots of soil-grown pea plants. J Bacteriol 1989, 171(10):5668-5671.

10. Yao J, Allen C: Chemotaxis is required for virulence and competitive fitness of the bacterial wilt pathogen Ralstonia solanacearum. J Bacteriol 2006, 188(10):3697-3708.

11. Bai F, Branch RW, Nicolau DV, Pilizota T, Steel BC, Maini PK, Berry R: Conformational spread as a mechanism for cooperativity in the bacterial flagellar switch. Science 2010, 327(5966):685-689.

12. Vladimirov N, Libiedz D, Sourjik V: Predicted auxiliary navigation mechanism of peritrichously flagellated chemotactic bacteria. PLOS Comput Biol 2010, 6(3):e1000717.

13. Maddock JR, Shapiro L: Polar location of the chemoreceptor complex in the Escherichia coli cell. Science 1993, 259:1717-1723.

14. Sourjik V, Berg HC: Localization of components of the chemotaxis machinery of Escherichia coli using fluorescent protein fusions. $\mathrm{Mol}$ Microbiol 2000, 37(4):740-751.

15. Kentner D, Sourjik V: Spatial organization of the bacterial chemotaxis system. Curr Opin Microbiol 2006, 9(6):619-624.

16. Koebnik R: TonB-dependent trans-envelope signalling: the exception or the rule? Trends in Microbiology 2005, 13:343-347.

17. Blanvillain S, Meyer D, Boulanger A, Lautier M, Guynet C, Denancé N, Vasse J, Lauber E, Arlat M: Plant carbohydrate scavenging through tonbdependent receptors: a feature shared by phytopathogenic and aquatic bacteria. PLoS One 2007, 2(2):e224.
18. Danhorn T, Fuqua C: Biofilm formation by plant-associated bacteria. Annu Rev Microbiol 2007, 61:401-422.

19. Amano A: Bacterial adhesins to host components in periodontitis. Periodontol 2000 2010, 52:12-37.

20. Hickman JW, Tifrea DF, Harwood CS: A chemosensory system that regulates biofilm formation through modulation of cyclic diguanylate levels. Proc Natl Acad Sci USA 2005, 102(40):14422-14427.

21. Craig L, Pique ME, Tainer JA: Type IV pilus structure and bacterial pathogenicity. Nat Rev Microbiol 2004, 2(5):363-378.

22. Pizarro-Cerdá J, Cossart P: Bacterial adhesion and entry into host cells. Cell 2006, 124(4):715-727.

23. Cotter SE, Surana NK, St Geme JW: Trimeric autotransporters: a distinct subfamily of autotransporter proteins. Trends Microbiol 2005, 13(5):199-205.

24. Koretke KK, Szczesny P, Gruber M, Lupas AN: Model structure of the prototypical non-fimbrial adhesin YadA of Yersinia enterocolitica. J Struct Biol 2006, 155(2):154-161.

25. Mazar J, Cotter PA: Topology and maturation of filamentous haemagglutinin suggest a new model for two-partner secretion. $\mathrm{Mol}$ Microbiol 2006, 62(3):641-654.

26. Hayward AC: The hosts of Xanthomonas. In Xanthomonas. Edited by: Swings JG, Civerolo EL. London UK: Chapman and Hall; 1993:1-119.

27. Vauterin L, Hoste B, Kersters K, Swings J: Reclassification of Xanthomonas. Int J Syst Bacteriol 1995, 45:472-489.

28. Dye DW, Bradbury JF, Goto M, Hayward AC, Lelliott RA, Schroth MN: International standards for naming pathovars of phytopathogenic bacteria and a list of pathovar names and pathotype strains. Rev Plant Pathol 1980, 59(4):153-168.

29. Alavi SM, Sanjari S, Durand F, Brin C, Manceau C, Poussier S: Assessment of the genetic diversity of Xanthomonas axonopodis pv. phaseoli and Xanthomonas fuscans subsp. fuscans as a basis to identify putative pathogenicity genes and a type III secretion system of the SPI- 1 family by multiple suppression subtractive hybridizations. App/ Environ Microbiol 2008, 74(10):3295-3301.

30. Rademaker JLW, Louws FJ, Schultz MH, Rossbach U, Vauterin L, Swings J, de Bruijn F: A comprehensive species to strain taxonomic framework for Xanthomonas. Phytopathology 2005, 95(9):1098-1111.

31. da Silva AC, Ferro JA, Reinach FC, Farah FC, Furlan LR, Quaggio RB, Monteiro-Vitorello CC, Van Sluys MA, Almeida NF, Alves LMC, do Amaral AM, Bertolini MC, Camargo LE, Camarotte G, Cannavan F, Cardozo J, Chambergo F, Ciapina LP, Cicarelli RM, Coutinho LL, Cursino-Santos JR, ElDorry H, Faria JB, Ferreira AJ, Ferreira RC, Ferro MI, Formighieri EF, Franco MC, Greggio CC, Gruber A, Katsuyama AM, Kishi LT, Leite RP, Lemos EG, Lemos MV, Locali EC, Machado MA, Madeira AM, MartinezRossi NM, Martins EC, Meidanis J, Menck CF, Miyaki CY, Moon DH, Moreira LM, Novo MT, Okura VK, Oliveira MC, Oliveira VR, Pereira HA, Rossi A, Sena JA, Silva C, de Souza RF, Spinola LA, Takita MA, Tamura RE, Teixeira EC, Tezza Rl, Trindade dos Santos M, Truffi D, Tsai SM, White FF, Setubal JC, Kitajima JP: Comparison of the genomes of two Xanthomonas pathogens with differing host specificities. Nature 2002, 417(6887):459-463.

32. Thieme F, Koebnik R, Bekel T, Berger C, Boch J, Büttner D, Caldana C, Gaigalat L, Goesmann A, Kay S, Kirchner O, Lanz C, Linke B, McHardy AC, Meyer F, Mittenhuber G, Nies DH, Niesbach-Klosgen U, Patschkowski T, Ruckert C, Rupp O, Schneiker S, Schuster SC, Vorholter FJ, Weber E, Puhler A, Bonas U, Bartels D, Kaiser O: Insights into genome plasticity and pathogenicity of the plant pathogenic bacterium Xanthomonas campestris pv. vesicatoria revealed by the complete genome sequence. $J$ Bacteriol 2005, 187(21):7254-7266.

33. Roumagnac P, Gagnevin L, Gardan L, Sutra L, Manceau C, Dickstein ER, Jones J, Rott P, Pruvost O: Polyphasic characterization of xanthomonads isolated from onion, garlic and Welsh onion (Allium spp.) and their relatedness to different Xanthomonas species. Int I Syst Evol Microbiol 2004, 54(1):15-24.

34. Wojciechowski MF, Lavin M, Sanderson MJ: A phylogeny of legumes (Leguminosae) based on analysis of the plastid matK gene resolves many well-supported subclades within the family. Am J Bot 2004, 91:1846-1862.

35. Chen SL, Hung CS, Pinkner JS, Walker JN, Cusumano CK, Li Z, Bouckaert J, Gordon J, Hultgren S: Positive selection identifies an in vivo role for FimH 
during urinary tract infection in addition to mannose binding. Proc Nat/ Acad Sci USA 2009, 106(52):22439-22444.

36. He YQ, Zhang L, Jiang BL, Zhang ZC, Xu RQ, Tang DJ, Qin J, Jiang W, Zhang X, Liao J, Cao JR, Zhang SS, Wei ML, Liang XX, Lu GT, Feng JX, Chen B, Cheng J, Tang JL: Comparative and functional genomics reveals genetic diversity and determinants of host specificity among reference strains and a large collection of Chinese isolates of the phytopathogen Xanthomonas campestris pv. campestris. Genome Biol 2007, 8(10):R218.

37. Nielsen R: Statistical tests of selective neutrality in the age of genomics. Heredity 2001, 86:641-647.

38. Eyre-Walker A: Changing effective population size and the McDonaldKreitman test. Genetics 2002, 162:2017-2024.

39. Sawyer S, Hartl D: Population genetics of polymorphism and divergence. Genetics 1992, 132:1161-1176.

40. Charlesworth J, Eyre-Walker A: The rate adaptive evolution in enteric bacteria. Mol Biol Evol 2006, 23:1348-1356.

41. Chen SL, Hung CS, Xu J, Reigstad CS, Magrini V, Sabo A, Blasiar D, Bieri T, Meyer RR, Ozersky P, Armstrong JR, Fulton RS, Latreille JP, Spieth J, Hooton TM, Mardis ER, Hultgren SJ, Gordon JI: Identification of genes subject to positive selection in uropathogenic strains of Escherichia coli: a comparative genomics approach. Proc Natl Acad Sci USA 2006, 103(15):5977-5982.

42. Petersen L, Bollback JP, Dimmic M, Hubisz M, Nielsen R: Genes under positive selection in Escherichia coli. Genome Res 2007, 17(9):1336-1343.

43. Weber E, Koebnik R: Positive selection of the Hrp pilin HrpE of the plant pathogen Xanthomonas. J Bacteriol 2006, 188(4):1405-1410.

44. Manson MD, Armitage JP, Hoch JA, Macnab RM: Bacterial locomotion and signal transduction. J Bacteriol 1998, 180:1009-1022.

45. Bernstein HD: Are 'autotransporters' really transporters? Trends in Microbiology 2007, 15:441-447.

46. Gerlach RG, Hensel M: Protein secretion systems and adhesins: the molecular armory of Gram-negative pathogens. Int J Med Microbiol 2007, 297(6):401-415.

47. Wang L, Makino S, Subedee A, Bogdanove AJ: Novel candidate virulence factors in Rice pathogen Xanthomonas oryzae pv. oryzicola as revealed by mutational analysis. Appl Environ Microbiol 2007, 73:8023-8027.

48. Darsonval A, Darrasse A, Durand K, Bureau C, Cesbron S, Jacques MA: Adhesion and fitness in the bean phyllosphere and transmission to seed of Xanthomonas fuscans subsp. fuscans. Mol Plant Microbe Interact 2009, 22(6):747-757.

49. Schluter D: The Ecology of Adaptive Radiation. Oxford: University Press; 2000.

50. Rundle RJ, Price T: Adaptive radiation, nonadaptive radiation, ecological speciation and nonecological speciation. Trends Ecol Evol 2009, 24(7):394-399.

51. Cohan FM: Sexual isolation and speciation in bacteria. Genetica 2002, 116(2-3):359-370.

52. Galperin MY: A census of membrane-bound and intracellular signal transduction proteins in bacteria: bacterial IQ, extroverts and introverts. BMC Microbiol 2005, 5:35.

53. Gardiner A, Barker D, Butlin RK, Jordan WC, Ritchie MG: Drosophila chemoreceptor gene evolution: selection, specialization and genome size. Mol Ecol 2008, 17(7):1648-1657.

54. Young JM, Park DC, Shearman HM, Fargier E: A multilocus sequence analysis of the genus Xanthomonas. Syst Appl Microbiol 2008, 31(5):366-377.

55. Fenton A, Antonovics J, Brockhurst MA: Inverse-gene-for-gene infection genetics and coevolutionary dynamics. Am Nat 2009, 174(6):E230-E242

56. Morris CE, Sands DC, Vinatzer BA, Glaux C, Guilbaud C, Buffière A, Yan $S$, Dominguez $\mathrm{H}$, Thompson BM: The life history of the plant pathogen Pseudomonas syringae is linked to the water cycle. ISME J 2008, 2:321-334

57. Vauterin L, Rademaker J, Swings J: Synopsis on the taxonomy of the genus Xanthomonas. Phytopathology 2000, 90(7):677-682.

58. Altschul SF, Madden TL, Schäffer AA, Zhang J, Zhang Z, Miller W, Lipman D: Gapped BLAST and PSI-BLAST: a new generation of protein database search programs. Nucleic Acids Res 1997, 25(17):3389-3402.

59. Hammer $\varnothing$, Harper DAT, Ryan PD: Past: paleontological statistics software package for education and data analysis. Palaeontologia Electronica 2001, 4(1):art 4.

60. Thompson JD, Higgins DG, Gibson TJ: CLUSTAL W: improving the sensitivity of progressive multiple sequence alignment through sequence weighting, position-specific gap penalties and weight matrix choice. Nucleic Acids Res 1994, 22:4673-4680.

61. Hall TA: Bioedit: a user-friendly biological sequence alignment editor and analysis program for Windows 95/98/NT. Nucleic Acids Symposium Series 1999, 41:95-98.

62. Marchler-Bauer A, Anderson JB, Chitsaz F, Derbyshire MK, DeWeese-Scott C, Fong JH, Geer LY, Geer RC, Gonzales NR, Gwadz M, He S, Hurwitz DI, Jackson JD, Ke Z, Lanczycki CJ, Liebert CA, Liu C, Lu F, Lu S, Marchler GH, Mullokandov M, Song JS, Tasneem A, Thanki N, Yamashita RA, Zhang D, Zhang N, Bryant SH: CDD: specific functional annotation with the Conserved Domain Database. Nucleic Acids Res 2009, 37:205-10.

63. Rozas J, Sánchez-DelBarrio JC, Messeguer X, Rozas R: DnaSP, DNA polymorphism analyses by the coalescent and other methods. Bioinformatics 2003, 19(18):2496-2497.

64. McDonald JH, Kreitman M: Adaptive protein evolution at the Adh locus in Drosophila. Nature 1991, 351(6328):652-654.

65. Rice WR: Analyzing tables of statistical tests. Evolution 1989, 43:223-225.

66. Yang Z, Nielsen R: Codon-substitution models for detecting molecular adaptation at individual sites along specific lineages. Mol Biol Evol 2002, 19(6):908-917.

67. Yang Z: PAML: a program package for phylogenetic analysis by maximum likelihood. Comput Appl Biosci 1997, 13(5):555-556.

doi:10.1186/1471-2148-11-67

Cite this article as: Mhedbi-Haji et al.: Sensing and adhesion are adaptive functions in the plant pathogenic xanthomonads. BMC Evolutionary Biology 2011 11:67.

\section{Submit your next manuscript to BioMed Central and take full advantage of:}

- Convenient online submission

- Thorough peer review

- No space constraints or color figure charges

- Immediate publication on acceptance

- Inclusion in PubMed, CAS, Scopus and Google Scholar

- Research which is freely available for redistribution
Ciomed Central 